\title{
Study on Functional Food Formula Ingredients
}

\author{
Jing Shi, Xiaofeng Sh, Siyang Liu * \\ Xi'an Medical University, Xi'an, Shaanxi, 710021
}

Keywords: Functional Food, Formula Ingredients, Food Industry

\begin{abstract}
Functional food ingredients refers to raw materials that provide the main functional ingredients for foods that have nutritional, sensory and physiological activities. These ingredients can enhance the body's constitution, prevent disease, help restore health, regulate body rhythm and delay aging. Functional food ingredients can be used as ingredients for health food products, as well as raw materials for specialty nutritional foods, and are said to be the soul of functional foods, which are of great significance to improving people's nutrition and health as a whole, and to a large extent promoted Functional food industry development. Functional foods have become one of the most dynamic new areas of food processing in the world today. With the improvement of processing technology, social environment and market environment, as well as the improvement of people's living standards and cognition, functional foods will be the mainstream of the food processing industry in the 21st century. However, the research and development of functional food ingredients is undoubtedly a functional Food industry one of the main directions of development.
\end{abstract}

\section{Introduction}

In recent years, Chinese rapid development of the nutritional industry, but in the "second five" Chinese development of the nutritional industry environment, from the demand level, the potential is still very large, and for a long time is a sunrise industry, as part of Chinese nutrition industry Of functional foods have very promising development prospects. Only $20 \%$ of functional foods occupy the total scale of Chinese nutrition industry. As the 21st century food and functional foods have enjoyed a growth rate of $20 \%$ in recent years and 2008 sales of 61.7 billion yuan However, compared with the developed countries in the United States and Japan, there is still a long way to go. With the aging of population in our country, the expansion of sub-health population, the serious situation of residents' lack of trace elements and the development of the third generation function Food is imminent, the third generation of functional foods is extracted from the active ingredients in the raw materials, and then added to the food, so that it has entered a higher level in terms of efficacy, safety and technological content, which on our functional foods The development of research proposed a higher level of technology. In addition, with the economic development of our country, the improvement of people's living standards and the ever-expanding purchasing power will promote the development of the functional food industry. Generally, when the per capita GDP of a country exceeds 1,000 US dollars, the functional food industry will enter a rapid expansion period. According to statistics from related departments, in 2007, Chinese per capita GDP has exceeded 2,000 U.S. dollars and its Engel coefficient has reached 36\%. This indicates that Chinese functional food industry will enter a period of continuous expansion.

\section{Chinese functional food ingredients industry development status quo}

Technical weakness, lack of product innovation, functional food ingredients have always been "criticized" place, through the research and development department of enterprises that (survey questionnaire see the attached table), Chinese production of functional food ingredients manufacturers have independent research and development The center only accounted for 36\%, without R \& D department occupy 64\%. For the R \& D department, we conducted a further investigation and found that the company's R \& D team accounted for the largest proportion of 10 or less, followed by $10-100$ people, the proportion of $34 \%$, with more than 100 research and 
development team of enterprises also mainly Only $10 \%$ of the large-scale enterprises concentrated in the industry.

As can be seen from the survey results, no matter from the number of R \& D department or from scientific research personnel, the functional food ingredients enterprises in our country have a long way to go in order to meet the public's ever-increasing demand for functional foods. As the production of food ingredients enterprises must continue to study and develop new products to meet consumer demand, will be more competitive in the market, made significant progress.

Chinese functional food ingredients industry started relatively late, most of the existing domestic manufacturers of functional food ingredients manufacturer at the end of the 20th century and early 21st century, as can be seen from Figure 3.3, the manufacturing enterprises to purchase scientific research equipment for lack of funds, research Equipment assets growth slowed down in 2008 by the economic crisis, the growth rate dropped significantly in 2009, a slight increase in growth rate, scientific research and production equipment, investment, production equipment has failed to meet the requirements of the production of functional materials have been developed with the request , Which limits the production of new varieties of functional food ingredients, so that many types of functional food ingredients in the country can not be mass-produced, resulting in a relatively low conversion rate of scientific and technological achievements.

Function The new food ingredients can be added to health foods as ingredients, as well as special nutritional foods in the form of raw materials, sometimes even directly. Functional food ingredients, after 30 years of reform and opening up the development, especially since the nineties, has been rapid development, some functional food ingredients have been very good foundation, the annual output of more than 10,000 tons, working-class in the city Has occupied a place with good market prospects and relatively wide coverage. However, due to the fact that the functional food ingredient industry in China is still in an ascendant stage of development, there are some constraints in its development that have hindered the rapid, healthy and sustainable development of the entire industry.

Consumer awareness of the ingredients of the functional ingredients is also one of the factors that can not be ignored. Julian Mellentin, Ph.D., director of consulting at New Nutrition Business, a London-based research firm, said: "The primary factor consumers consider when choosing functional foods is whether they make them feel effective or not, Perceived effectiveness, it is possible to get into trouble. " Therefore, consumers' understanding of the functional ingredients and characteristics of functional food ingredients is an important factor that affects the application and promotion of functional food ingredients. In addition, special care needs to be taken that consumers are reluctant to change their intrinsic lifestyle because of functional foods.

\section{Chinese functional food ingredients industry development}

Chinese rapid economic development, the rapid improvement of people's living standards, the increasingly high demand for quality of life, the face of the high demand for healthy living, in order to meet people's demand for healthy food ingredients, enterprises and scientific research units around the focus of research and development both Functional food ingredients that can satisfy the taste and improve health have some new functional ingredients already on the market. At present, the new functional food ingredients represented by functional sugars (xylooligosaccharides, xylitol, dietary fiber, etc.) In the food, health products, and other fields has been very widely used, while the current emerging ingredients such as immune function to enhance immunity, antioxidant herbs and plant ingredients, slimming and beauty food ingredients, anti-allergy food ingredients, functional foods for menopause Materials, anti-stress function food ingredients, brain function of food ingredients have made breakthroughs in all walks of life. In the 12th Five-year Development Plan of the national food industry recently released by relevant state departments, the direction of development of food ingredients in our country is that it is nutritious, green, healthy, safe and reliable. With the development of our country's nutrition and health industry, green and healthy have become the mainstream of the development of functional food ingredients.

China for each of the research and development of functional food ingredients should deal with 
their functional characteristics, functional factors have a clear rule, not the better the functional effect of the market demand, the greater the volume so that the oversupply, the market The imbalance between supply and demand, because the demand for functional ingredients is not a single functionally controlled, and when it comes to the effective use and units, each consumer's economic burden is very different, which will enable consumers Make different choices that affect their demand. Therefore, according to the development and market prospects, a clear definition of the location of each functional food ingredients, not just by its functional level to determine market share.

As a functional food with disease prevention and disease resistance, publicity should be expanded so that consumers truly understand and accept from the heart, like daily necessities, become a kind of food that consumers are willing to buy. This can start with the functional food ingredients, allowing the public to understand the basic ingredients, to eliminate the old concept of the past, as a functional factor into the lives of ordinary people in the convenience food and snack foods commonly used. Can follow the early development of our country into the market of milk powder (that is, the so-called infant formula) development characteristics, the use of such products is convenient, easy to absorb nutrients and so on, in the market has been more widely used, the current Not only as a family baby food, but also for the elderly, middle-aged people eat. Therefore, the development of functional food ingredients, we must first meet the consumer mainstream that is green, healthy, on the basis of the development of research, product features developed to be obvious, allowing consumers to perceive and prices to enable consumers to accept, Produced functional foods will have a market, the two promote each other, have gained greater growth. To clear market share, market capacity for production, supply and demand to achieve the general balance of supply can be appropriately greater than demand, gradual development step by step.

\section{Chinese functional food ingredients industry development proposals}

With the aging of the population and the increase of chronic diseases, the rapid increase of medical expenses has aggravated the burden on the government and consumers. At the same time, people are more concerned about food safety and environmental protection, which have promoted the birth and development of functional food ingredients industry. In addition, The structure is not reasonable, resulting in the expansion of Chinese sub-health population, the number of non-communicable chronic diseases increased dramatically. In this sense, the development of functional food ingredients industry is imperative, but in the face of the backward management practices of government industry and the lack of residents' understanding, it is necessary for the government to take positive industrial policies to support it. Functional food ingredients industry involves the supply of agricultural raw materials, science and education personnel training, food processing and manufacturing, to form a strong adhesion industry chain, no doubt the government is the leading industrial chain. Japan's functional ingredients industry from scratch, from small to large, and the government's active promotion are inseparable, at present, Japan has functional foods research as a strategic national key international competition era to advance. The government should carry out policies on functional ingredients industry policies, standards, laws and regulations. Relevant management departments of the government should conduct correct public opinion guidance and raise the overall health meaning so that the residents of the whole society will realize that the development of functional food ingredients is the need of social development and the protection of people's health.

The establishment of special funds to support the development of functional food ingredients business $\mathrm{R} \& \mathrm{D}$ center, the introduction of talent, in-depth research and development for the enterprise product innovation and production technology innovation provides a direct and effective technical support, the enterprise innovation results to improve its conversion rate. Such as Sichuan Wuliangye, Tianjin dynasty, Jiangsu Yurun and a number of representative of the enterprise technology center, continue to increase investment in science and technology, development of technological innovation projects, the formation of competitiveness. Chinese functional food ingredients industry should emerge in the critical period of the development of the ingredients 
industry leader, give play to the enterprise as the main advantage of technological innovation, increase the scientific and technological content, and narrow the gap with the international advanced level.

Engage foreign well-known researchers in the industry to set up Chinese functional food ingredients industry development expert advisory committee for the development of functional ingredients industry counsel; like the Food Industry Association has established liquor, beer, potatoes and other 11 professional committees, play close to the enterprise to understand Enterprises, enterprises in place for more effective and more significant advantages, in the industry self-regulation, development of standards, information consulting, technical training, market development, and so do a rich and efficient work; organized annual meeting of the development of functional ingredients industry forum, Participate in the development of major functional food ingredients industry forums and professional exhibitions at home and abroad to promote industrial cooperation and technological exchanges so that universities, research institutes and enterprises can truly take a global view and walk with counterparts in the world giants to take the lead in the development of functional food ingredients industry.

\section{Conclusion}

The development of functional food ingredients industry also needs more detailed development planning and support. This article only analyzes the current situation of industry development macroscopically, finds out the bottleneck of development and puts forward some suggestions. However, there is not a deeper level from micro and professional From the perspective of analysis, put forward the vision, analysis of enterprise productivity, key technologies; from the industry level, the idea of the establishment of a proprietary trade association for the state and enterprises to establish a bridge and link.

\section{References}

[1] You X. Development of Functional Food Additives and Ingredients at Home and Abroad [J] .Chinese Condiment, 2009, (9)

[2] Ma Yuxia, Wang Yong, Gao Yang. Chinese status quo and development of functional foods [J].Chinese Journal of Food and Nutrition, 2005, (4):32-34

[3] Fang Hui. The development of functional food ingredients [J]. Journal of Food Safety, 2009, (2): 2-126

[4] Ling Guanting. Brief talk about functional food additives [J]. Fine and Specialty Chemicals, 1999, (12): 3-7

[5] Yan Zuomei, Gu Xuefeng. Advances in the Function and Development Prospect of Soy Isoflavones [J]. Soybean Bulletin, 2006, (1): 34-35

[6] You X. Foreign lycopene and other functional beverages development trend [J]. China Food Additives.2005 (5): 2-4

[7] Ren Hong, Yang Yang, Shi Defang. Advances in the application of lutein in functional foods [J]. Food Research and Development, 2006, (4)144-146 